\title{
Comparisons Between Construction of Pre Engineered Building and Conventional Building
}

\author{
M.S.K.Chaitanya ${ }^{1}$, M.Venkat Rao ${ }^{2}$, G.Aditya ${ }^{3}$ \\ ${ }^{1}$ M.S.K.Chaitanya B.E in civil engineering in Andhra University, PGDQS in NICMAR-Hyderabad, India \\ ${ }^{2}$ M.Venkat Rao M.tech in civil engineering in Andhra University, India \\ ${ }^{3}$ G.Aditya M.tech in civil engineering in Andhra University, India
}

\begin{abstract}
The present construction methodology for buildings calls for the best aesthetic look, high quality \& fast construction, cost effective \& innovative touch. India being a developed country massive house building construction is taking place in various parts of the country. Since 30\% of Indian population lives in towns and cities hence construction is more in the urban places. Hence one has to think for alternative construction system like pre-engineered steel buildings. India has an installed steel capacity of 35 to 40 million tones \& apparent steel consumption is around 27 to 30 million tones. There is a surplus capacity of flat steel products available in India particularly of hot and cold rolled sheets. In pre-engineered building concept the complete designing is done at the factory and the building components are brought to the site in knock down condition. These components are then fixed/jointed at the site and raised with the help of cranes. The pre-engineered building calls for very fast construction of buildings and with good aesthetic looks and quality construction.
\end{abstract}

Keywords: Conventional Building, Cost Analysis, Hot and Cold Rolled Sheets, Pre Engineered Building

\subsection{Objective:}

\section{Introduction}

- cost comparison between Pre Engineered Building and Conventional building

- Estimation of quantities for all the items of Engineering Block (Pre Engineered Building) in Indu Projects Ltd.

- Estimation of quantities for all the items of Office building (Conventional building) in Indu Projects Ltd..

- To make a comparison between the Pre Engineered Building and Conventional building and to bring out the variations in cost and time of construction.

\subsection{Methodology:}

Total Structural steel is calculated from the drawings by using steel tables as per IS Codes. Steel quantities are calculated in tones. Method of estimation is used for calculating the quantities of the items involved in the estimation. Different components of Pre Engineered Building are estimated and rates for the same are available in market rates. While working out for the rates of the materials all the constants are taken from JOGLEKAR.

\subsection{Source:}

- The main source of information for the project is from Indu Projects Ltd., $13^{\text {th }}$ Phase, KPHB, Kukatapally, Hyderabad-72.

- $\quad$ Also collected data from the sites like

$\checkmark \quad$ Japan Metal Building Systems Pvt Ltd, Bangalore.

$\checkmark$ Kirby Steel Structure, Hyderabad..

- Collected some of the data from internet.

\subsection{Limitations:}

- Because of Pre Engineered Building is Mechanical Structure, we estimate the total structural steel with the help of the technical staff Mr. Sanjeev, Japan metal building systems, which consumed a lot of time.

- The data flow from HIL office to outsiders is being restricted, we completed this paper with some assumptions

\subsection{Scope:}

- The construction technology has advanced since the beginning from primitive construction technology to the present concept of modern house buildings. The present construction methodology for buildings calls for the best aesthetic look, high quality \& fast construction, cost effective \& innovative touch 
- In pre-engineered building concept the complete designing is done at the factory and the building components are brought to the site in knock down condition. These components are then fixed / jointed at the site and raised with the help of cranes

\section{About Pre-Engineered Building}

\subsection{Pre-Engineered Metalled Buildings the Latest Trend in Building Construction}

Pre-Engineered Steel Buildings use a combination of built-up sections, hot rolled sections, cold formed elements and profiled steel sheets which provide the basic steel frame work with a choice of single skin sheeting with added insulation or insulated sandwich panels for roofing and wall cladding or brick wall. The concept is designed to provide a complete building envelope system which is air tight, energy efficient, optimum in weight and cost and, above all, designed to fit user requirement like a well fitted glove.

These Pre-Engineered Steel Buildings can be fitted with different structural accessories including mezzanine floors, canopies, fascias, interior partitions etc. The building is made water-tight by use of special mastic beads, filler strips and trims. This is a very versatile building system and can be finished internally to serve any required function and accessorized externally to achieve attractive and distinctive architectural styles. It is most suitable for any low-rise building and offers numerous benefits over conventional buildings.

Pre-engineered buildings are generally low rise buildings; however the maximum eave heights can go up to 25 to 30 meters. Low rise buildings are ideal for offices, houses, showrooms, shop fronts etc. The application of pre-engineered concept to low rise buildings is very economical and speedy. Buildings can be constructed in less than half the normal time especially when complimented with other engineered sub-systems.

The most common and economical type of low-rise building is a building with ground floor and two intermediate floors plus roof. The roof of a low rise building may be flat or sloped. Intermediate floors of low rise buildings are made of mezzanine systems. Single storied houses for living take minimum time for construction and can be built in any type of geographic location like extreme cold hilly areas, high rain prone areas, plain land, extreme hot climatic zones etc.

\subsection{The basic parameters that define a pre-engineered buildings are:}

\section{Building Width}

No matter what primary framing system is used, the building width is defined as the distance from outside of eave strut of one sidewall to outside of eave strut of the opposite sidewall. Building width does not include the width of Lean-To buildings or roof extensions.

\section{Building Length}

The distance between the outside flanges of end wall columns in opposite end walls is the building length. It is a combination of several bay lengths.

\section{Building Height}

Building height is the eave height which usually is the distance from the bottom of the main frame column base plate to the top outer point of the eave strut. When columns are recessed or elevated from finished floor, eave height is the distance from finished floor level to top of eave strut.

4. Roof Slope $(\mathrm{x} / \mathbf{1 0})$ :

This is the angle of the roof with respect to the horizontal. The most common roof slopes are $0.5 / 10$ and 1/10. Any practical roof slope is possible.

\section{End bay length}

The distance from outside of the outer flange of end wall columns to center line of the first interior rime column.

\section{Interior bay length}

The distance between the center lines of two adjacent interior main frame columns. The most common bay lengths are $6 \mathrm{~m}, 7.5 \mathrm{~m}$ and $9 \mathrm{~m}$.

7. Design Loads

Pre-engineered buildings are designed for the following minimum loads:
Roof
Live Load: 0.57
$\mathrm{kN} / \mathrm{m}^{2}$

Design Wind Speed: $110 \mathrm{~km} / \mathrm{h}$

Design for snow loads, earth quake loads, collateral loads, crane loads or any other loading condition, if required must be specified at the time of request for quotation.

Loads are applied in accordance with the latest American codes and standards applicable to pre-engineered buildings unless otherwise requested at the time of request for quotation. 


\subsection{Components of Pre-engineered steel building}

\section{Main Frame}

Main framing basically includes the rigid steel frames of the building. The PEB rigid frame comprises of tapered columns and tapered rafters (the fabricated tapered sections are referred to as built-up members). The tapered sections are fabricated using the state of art technology wherein the flanges are welded to the web. Splice plates are welded to the ends of the tapered sections. The frame is erected by bolting the splice plates of connecting sections together.

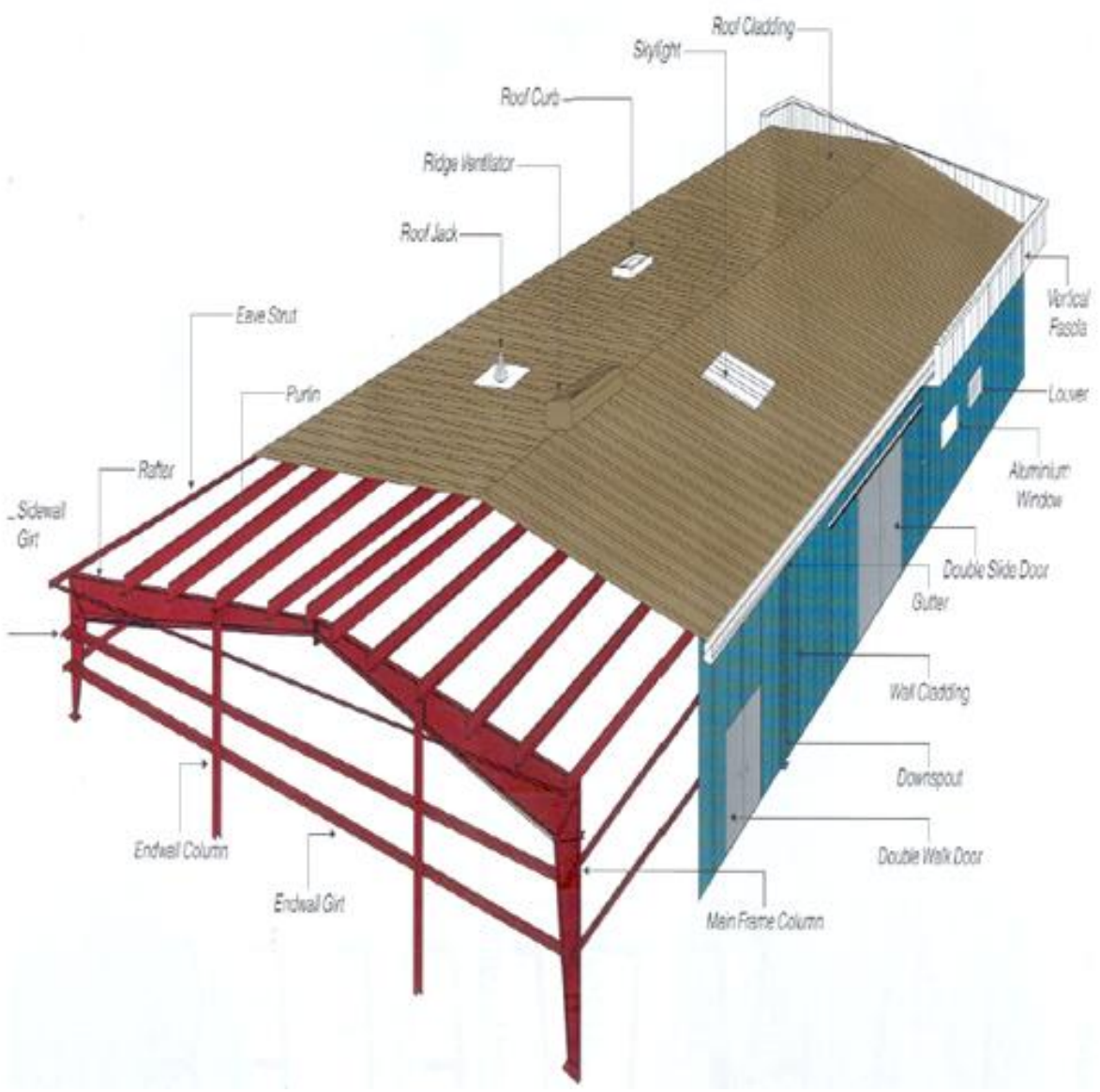

\section{Purlins, Girts And Eave Struts}

Purlins, girts and eave struts are also known as secondary cold-formed members. There is no welding involved in their preparation. They are prepared by just bending the steel coil giving it the desired shape ( $\mathrm{Z}$ shape for purlins and girts, and C-shape for eave struts).

Purlins: Purlins are the secondary members are for supporting the roof panels \& wall cladding. Girts are used on the walls and eave struts are used at the intersection of the sidewall and the roof. Secondary members have two other functions: they act as struts that help in resisting part of the longitudinal loads that are applied on the building such as wind and earthquake loads, and they provide lateral bracing to the compression flanges of the main frame members thereby increasing frame capacity.

\section{Panels And Insulation}

Single skin profile or ribbed steel sheets are used as roof and wall sheeting, roof and wall liners, partition and soffit sheeting. The steel sheets are generally made from steel coils. Minimum thickness of steel coils used is $0.5 \mathrm{~mm}$ high tensile steel.

The steel sheets are normally of zincalume or galvanized bare and permanently colour coated or plain which can be coated at site after installation.

\section{Different type of Panels}

(i) Roof Panel

(ii) Wall \& Liner Panel

(iii) Mezzanine Deck Panel

(iv) Tempcon Flat Skin Panel 


\section{Paints And Finishes}

Normally the primary and secondary steel are coated with one coat (35 microns) of redoxide paint without any special treatment to steel. However, if some special paint has to be applied to steel in order to give better anti-corrosion properties etc. then the steel members have to be shot-blasted and then coated with the special paints.For houses inside \& outside painting on walls \& false ceiling are to be provided.

\section{Doors And Windows}

Steel or aluminium framed doors and windows are fixed to the purlins or the supporting profiled steel either by welding or bolted to the flanges already fixed to the purlins. Proper flashings are applied wherever necessary.

\section{False Ceiling}

This is usually required for residential building or offices. A metal frame work is hung from the ceiling and false ceiling of rigid boards are either bolted or placed over the frame work.

\section{Partition Walls}

This is usually required for residential building or offices. Partition wall comprises of two rigid boards having insulation sandwiched in between and fixed to the steel columns or supporting profiled steel and purlins. Alternatively prefab sandwich panels can also be fixed to the columns and purlins.

\section{Flooring}

Flooring is usually of conventional nature consisting of cement concrete. For intermediate floors metal decking sheet is fixed to purlins and concrete poured over it.

\section{Design Codes}

Design codes that govern the design procedures and calculations are as follows:-

Frame members (hot rolled or built-up) are in accordance with AISC (American Institute of Steel Construction) Specifications for the design, fabrication and erection of structural steel.

Light gauge cold-formed members are designed in accordance with AISI (American Iron and Steel Institute) Specification for the design of light gauge cold formed steel structural members.

IS: 8750 - 1987 : Code of practice for design loads of buildings \& structures.

IS: $800-1984$ : Code of practice for general construction in steel.

IS: 801-1975 : Code of practice for use of Cold formed light gauge Steel Structural Members in general building Construction

\section{Erection}

Steel framing members are delivered at site in pre-cut sizes, which eliminates cutting and welding at site. Being lighter in weight, the small members can be very easily assembled, bolted and raised with the help of cranes. This system allows very fast construction and reduces wastage and labour requirement. These buildings can then be provided with roof decking and wall cladding with metal profile sheets and proper insulation. The framing are so designed that electrical and plumbing services are part of it and can be very easily concealed.

For the latest developed technology on pre-fab residential house construction without steel columns \& purlins, the construction method begins with grouting of ' $\mathrm{C}$ ' channels to the floor on the periphery of the building. Thereafter placing $1.2 \mathrm{~mm}$ GI profiled sheets (of high depth crest) over the ' $\mathrm{C}$ ' channel and fixed with screws. Fixing of high density Rockwool or Polyurethane Foam or Expanded Polystyrene with adhesive on the crests on both sides. Then providing and fixing $8 \mathrm{~mm}$ cement particle boards on inner side and $10 \mathrm{~mm}$ cement particle boards on outer side of the profiled GI sheet, with screws, followed by fixing of a ' $\mathrm{C}$ ' channel on top of the GI profiled sheet. Then trusses are placed over the top ' $\mathrm{C}$ ' channel and purlins fixed to it at $1500 \mathrm{~mm}$ distance. Colour coated profile steel sheets are fixed to the purlins. GI ' $T$ ' frame work making a grid of $600 \mathrm{x}$ $600 \mathrm{~mm}$ hung from the trusses with GI rods for false ceiling frame work and $6-8 \mathrm{~mm} \mathrm{E}$ boards are placed over it.

For fixing of electrical accessories, grills, shelves and other miscellaneous services wooden supports are pre-fixed to the GI profiled sheet ceiling fan support is taken from the trusses. Doors \& windows frames are made of steel and fixed to the profiled GI sheet with proper flashings. Rain guard covers over windows made of steel are fixed to the profiled GI sheet of walls. The gaps between the cement particle boards are filled with aputty and finally painting is done on both sides of the walls.

\section{Maintenance}

In Pre-engineered Pre-fabricated steel houses the maintenance area is the roofing \& cladding. Steel roofing \& side wall cladding requires minimum maintenance. The roof should be inspected immediately after 
installation to check if cleaning of the roof has been carried out fully. It is very often seen that the drilled out metal and debris are not swept away. These can act as initiators of corrosion and lead to premature failures. In case of cement particle board walls painting required every 3-4 years. Installed roofing must be inspected atleast once a year. Any exposed metal that can rust or has rusted should be painted. Leaves, branches, and trash should be removed from gutters, at ridge caps and in corners. Also watch out for discharge from industrial stacks, and particulate matter and high sulphur exhaust from space heaters which could get piled up.

\subsection{Advantages of Pre Engineered Buildings}

1. Low initial cost due to

- Tapered built up structural members (columns \& rafters)

- Z Z shaped secondary members (purlins \& girts) that allow overlapping

- Foundations are fewer and lighter plan

2. Superior product quality

- Design quality is latest and consistent based on international codes

- Welding is professionally done

- Fabrication is as per quality

3. Fast project construction

- Anchor bolts are on site before the building

- Fabrication and delivery is faster due to standardization

- Since all members are field bolted erection takes place faster

\section{Functional Versatility}

- Modular construction before the building

- Large clear spans up to $100 \mathrm{~m}$

- Long bay spacing up to $13 \mathrm{~m}$ without jack beams

- Buildings are easily expandable in future

\section{Architectural Flexibility}

- Aesthetic features such as fascias, etc improve the panels

- Flashing and Trims come in various shapes and colors

- A wide range of wall and roof sheeting is available

6. Low maintaining and operating costs

- Virtually no maintenance for panels

- Eave gutters are washed annually

- Roofs are watertight

- Energy efficient roof and wall systems by using insulation

\subsection{Applications of Pre-Engineered Buildings}

Almost every conceivable building use has been achieved using the pre-engineered building approach. The most common applications of pre-engineered buildings are

\section{Industrial}
i. Factories
ii. Workshops
iii. Warehouses
iv. Car parking sheds
v. Slaughter houses
vi. Bulk product storage

Cold stores
i. Institutional
ii. Schools, Sports Halls
iii. Exhibition halls
iv. Hospitals
v. Theaters
vi. Auditoriums 


\section{Commercial}

i. Distribution centers

ii. Showrooms

iii. Supermarkets

iv. Fast food restaurants

v. Offices

vi. Labor camps

vii. Service stations

viii. Shopping centers

Aviation \& Military
i. Aircraft hangars
ii. Administration buildings
iii. Residential barracks

Agricultural

i. Poultry buildings

ii. Dairy farms

iii. Greenhouses

iv. Grain storage

v. Animal confinement

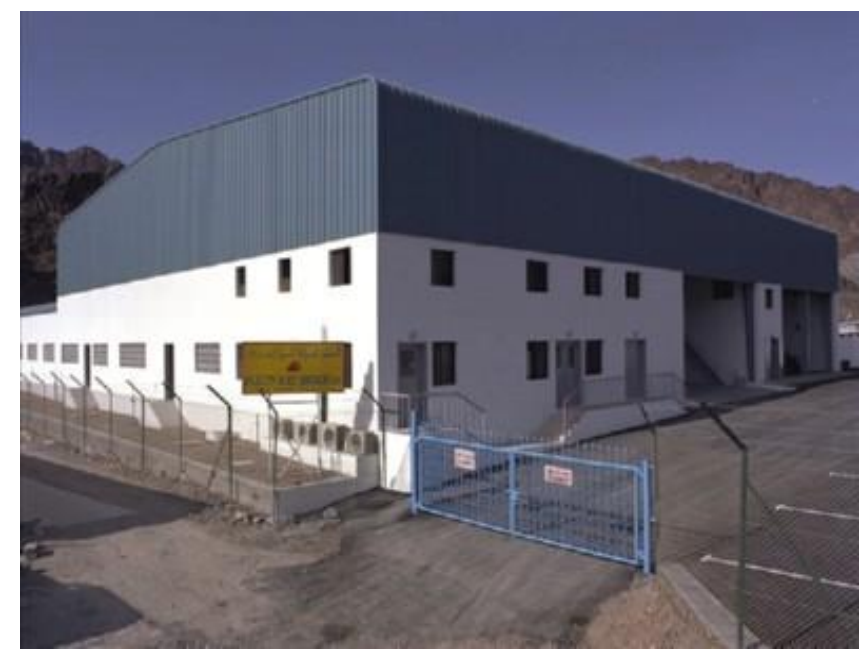

Building Type Workshop

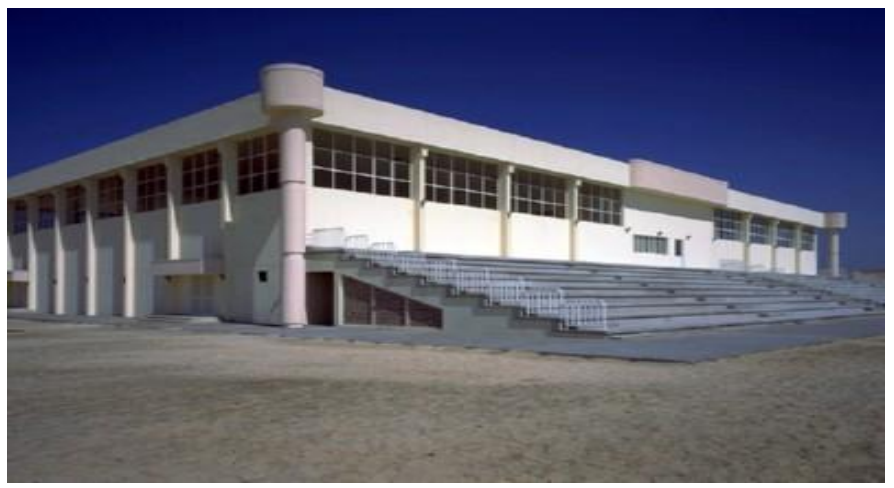

Building Type Auditorium

\subsection{Pre- Engineered \& Conventional Buildings Cost Advantages}

- Accurate Estimates. Computer-generated building techniques and material designs provide better estimates. Pre-engineered components go together without a problem, preventing expensive construction surprises.

- Cheaper to Build. Construction costs are significantly less. There's no welding or fabrication on site, and no waste. Material Is Cheaper. Computer-aided design in pre-engineered construction saves material and cost 
- Only One Structural Component Supplier. One company does the structural design work and furnishes the material components. This simplifies record keeping and eliminates waiting for supplies from different vendors.

- Good Energy Efficiency. Components fit together correctly with no gaps. Metal panels include insulation.

- Less Maintenance. Metal roof finishes are very durable, lasting much longer than the 15-20 years of conventional roofs. Finished metal panels clean easily and do not rust or lose their colors. Practically no structural maintenance is required.

- Cheaper Insurance. Metal construction reduces fire hazard-insurance companies sometimes reduce rates.

- Less Time to Build .A typical pre-engineered metal building takes less time to build and reduces financing costs.

- Attractive Appearance .Masonry trim can be added to the exterior to give a conventional appearance. Panels are available in a wide selection of baked-on colors for decorative choice.

- How Safe Are They? Metal-frame construction is inherently safe, able to withstand severe weather conditions

\section{Comparision Between Cost of Pre-Engineered Building and Cost of Conventional Building}

\begin{tabular}{|c|c|c|c|}
\hline S.No & Decsription & Pre-Engineered Building & Conventional Building \\
\hline 1 & Total cost of the building & Rs $3,01,21,050.30$ & Rs $24,74,490.58$ \\
\hline 2 & Plinth area in square meters & 1984 sq mts & $151.5 \mathrm{sq} \mathrm{mts}$ \\
\hline 3 & Cost of building for sq mst & Rs 15145.98 per sq mts & Rs $16,333.27$ per sq mts \\
\hline
\end{tabular}

From the above estimates it clearly say's that cost of the Pre-engineered building is less than that of conventional building and also less time is required for pre-engineered building than conventional building.

\subsection{Interpretation}

- Construction of Pre-engineered building involves less cost than that of the construction of the conventional building.

- The projects which have time constraint then we can go for the Pre-engineered buildings.

- For the construction of the temporary structures these Pre-engineered buildings are used because these components can be reusable.

\section{Conclusion}

Steel is a preferred material for construction, due to its various advantages like quality, aesthetics, economy and environmental conditions. This concept can have lot of scope in India, which can actually fill up the critical shortage of housing, educational and health care institutions, airports, railway stations, industrial buildings \& cold storages etc. Pre-engineered Metal building concept forms an unique position in the construction industry in view of their being ideally suited to the needs of modern Engineering Industry. It would be the only solution for large industrial enclosures having thermal and acoustical features. The major advantage of metal building is the high speed of design and construction for buildings of various categories.

\section{References}

[1] RANGAWALA, Estimation Costing and Valuation.

[2] B.N.DUTTA, Estimation and Valuation

[3] JOGLAKAR, Material and Labour constants.

[4] IS 1200, Method of measurement of building and civil engineering works.

[5] SP27-1987, Hand book of measurement of building works.

[6] R. AGOR, Steel tables. 